Running head: NARCISSISM AND CREATIVITY

From a Mirage to an Oasis:

Narcissism, Perceived Creativity, and Creative Performance:

\author{
Jack A. Goncalo \\ Cornell University \\ Francis J. Flynn \\ Stanford University \\ Sharon H. Kim \\ Cornell University
}

Word count: 9,485

IN PRESS, PERSONALITY AND SOCIAL PSYCHOLOGY BULLETIN

Address correspondence to:

Jack A. Goncalo

Cornell University

School of Industrial and Labor Relations

391 Ives Hall

Ithaca, NY 14853

Tel: 607-255-2085

Fax: 607-255-2261

e-mail: jag97@ cornell.edu 


\begin{abstract}
We examine the link between narcissism and creativity at the individual, relational, and group levels of analysis. We find that narcissists are not necessarily more creative than others but they think they are, and they are adept at convincing others to agree with them. In the first study, narcissism was positively associated with self-rated creativity, despite the fact that blind coders saw no difference between the creative products offered by those low and high on narcissism. In a second study, more narcissistic individuals asked to pitch creative ideas to a target person were judged by the targets as being more creative than were less narcissistic individuals, in part because narcissists were more enthusiastic. Finally, in a study of group creativity, we find evidence of a curvilinear effect: having more narcissists is better for generating creative outcomes (but having too many provides diminishing returns).
\end{abstract}

KEYWORDS: narcissism, creativity, self-enhancement, group dynamics 
"God is really an artist, like me...I am God, I am God, I am God."

Pablo Picasso

\section{From a Mirage to an Oasis: Narcissism, Perceived Creativity and Creative Performance}

The above quote captures the stereotype of highly creative people as self-aggrandizing, self-indulgent, and self-absorbed. According to some scholars, such displays of narcissism may be an inevitable byproduct of creative talent. Because creative people spend a great deal of time alone, are often absorbed in their work to the point of obsession, and refuse to conform to social conventions, they are likely to appear narcissistic to others (Barron \& Harrington, 1981). In contrast, some researchers propose that narcissism directly contributes to creativity because narcissists are motivated to generate novel ideas as a way to "stand out" and draw attention to themselves (Raskin, 1980).

In the present research, we advance a different view. We argue that narcissists are not necessarily more creative than others, but they think they are, and they are adept at convincing others to agree with them. Creativity is often judged by subjective evaluation rather than the satisfaction of objective criteria, both among practitioners (e.g., Sutton \& Hargadon, 1996) and among scholars (e.g., Amabile, 1982). Given the ambiguity involved in judging creative work, narcissists may be particularly skillful not only at convincing themselves of the high quality of their creative ideas, but at conveying their ideas with enough enthusiasm and confidence to impress their peers. Indeed, the traits that are typically associated with narcissism (e.g., self- 
confidence and self-esteem) may be well suited to support this social construction of their creative talents.

While this paints a dim view of narcissists' true creativity, we do not mean to suggest that narcissism is irrelevant to creative problem solving. Rather, we extend our analysis to the group level to suggest that narcissists are able to contribute to creative outcomes, but not on their own. Because narcissists crave attention for their contributions (John \& Robbins, 1994), they may shift the entire group toward a more competitive norm that, in group settings, motivates idea expression (Dugosh \& Paulus, 2005). In other words, narcissists may be highly effective at generating novel solutions to complex problems, so long as there is at least one other narcissist in the group who can compete with him or her for attention and support of their opinions. To wit, two narcissistic "heads" might be better than one because their tendency to engage in competitive dialogue benefits the group by prompting it to consider a wider range of potential solutions.

We tested these predictions in three studies that extend theory and research on narcissism and creativity in a number of important ways. First, we provide evidence of a link between narcissism and creativity that is akin to a social construction-narcissists are skillful in persuading others (as well as themselves) that they have creative ideas even when they do not. Second, we build on the extant narcissism literature by advancing a counterintuitive hypothesis - that narcissistic group members can inspire higher levels of creative performance from his or her colleagues, although the source of the group's creative output may not necessarily be the result of the narcissist's own creative contributions. Third, and more generally, we contribute to a broad scholarly interest in the determinants of creativity, demonstrating that 
narcissists are indeed linked to highly creative outcomes, but not owing to the fact that they are highly creative people.

\section{Narcissism and Individual Creativity}

Narcissism refers to a set of egocentric traits including self-admiration, self-centeredness, and self-regard (Sedikides, Rudich, Gregg, Kumashiro, \& Rusbult, 2004). Individuals scoring high in narcissism have a strong sense of entitlement and a constant need for attention and admiration (Bogart, Benotsch, and Pavlovic, 2004). They frequently use singular personal pronouns (e.g., I, me) in speech (Raskin \& Shaw, 1998) and fail to listen attentively to others (Kernis \& Sun, 1994). Narcissists report a lesser need for intimacy (Carroll, 1987) and have little empathy for their peers, even those in distress (Watson, Grisham, Trotter, \& Biderman, 1984). Perhaps more surprisingly, narcissists tend to emerge as leaders (Brunell, Gentry, Campbell, Hoffman, Kuhnert, \& Demaree, 2008), even at the highest levels of organizations (Chatterjee \& Hambrick, 2007).

Descriptions of highly creative people indicate that they are often highly narcissisticdriven only by their own desires and insensitive to the opinions of others (e.g., Macdonald \& Wilson, 2005). However, anecdotal accounts linking narcissism to creativity are hard to interpret because it is difficult to disentangle narcissists' objective creative performance from their own and others' perceptions of their creativity. On one hand, narcissism might be a trait, like openness to experience (McCrae, 1987), that predicts performance on creative tasks. For example, the tendency of narcissists to use "I" pronouns in speech might be indicative of a differentiation mindset that has been shown to stimulate divergent thinking (Wiekens \& Stapel, 2008). 
On the other hand, there is evidence to suggest that narcissists may not be more adept at coming up with creative ideas, just more likely to overestimate their creativity relative to others. Narcissists are self-aggrandizers; that is, they tend to give themselves too much credit for their past accomplishments and are overly optimistic about their future success (John \& Robbins, 1994). In a sample of undergraduate students, narcissism correlated strongly with the grades that participants expected to receive in their courses (i.e., narcissists predicted they would receive higher grades), although there was no correlation between narcissism and undergraduates' actual course grades (Farwell \& Wohlwend-Lloyd, 2008).

Building on this research, we expect to find significant self-enhancement from narcissists (relative to others) when asked to judge their own performance on a creative task. Most people, narcissistic or not, find it difficult to generate creative solutions because they are often constrained by their prior experiences (Ward, 1994; Duncker, 1945). Narcissists may be subject to similar constraints, but their tendency toward self-enhancement will make them less likely than others to recognize that their ideas are not especially novel. In other words, we do not expect to find a positive relationship between narcissism and individual creativity. Instead, we expect to find significant self-enhancement from narcissists when asked to judge their creative talents.

\section{Narcissism and Perceptions of Creative Talent}

Narcissists may not be creative, but their high levels of self-confidence may nevertheless influence the way others evaluate their ideas. Although researchers have numerous tools at their disposal for measuring creativity, there are many contexts in which creativity is judged by observers who lack rigorous criteria (Amabile, 1982; Taylor \& Barron, 1963) and are subject to attributional biases (Kasof, 1995). For example, in a qualitative study of Hollywood "pitches," 
Elsbach and Kramer (2003) found that judgments of creativity were influenced by perceptions of the "pitcher" and the extent to which they matched the prototypical traits of a highly creative person, such as "charismatic" and "witty." As one studio executive explained, "... someone who is enthusiastic and passionate can make a regular story sound spectacular (Elsbach \& Kramer, 2003: 290)."

This quote is revealing for two reasons. First, it highlights the fact that perceptions of creative ability may be separate from whether a product is objectively creative. Second, it suggests that certain behaviors of the person who pitches creative ideas, especially their energy, enthusiasm, and conviction, can prompt evaluators to judge their ideas to be more creative than they actually are. This second point dovetails with research on social influence in which behaviors that signal confidence, such as taking the head seat prior to a group discussion, can make one's ideas seem more plausible and convincing (Nemeth \& Wachtler, 1974).

We expect that narcissists may be at a significant advantage in these evaluations because they will be both highly confident that they are more creative than others and more inclined to publicly share these flattering self-views with people who are in a position to evaluate their ideas. In the absence of any objective information about an idea's creative quality or criteria on which to base such an evaluation, narcissists' self-aggrandizing behaviors may be persuasive, particularly because they match evaluators' prototypes of how highly creative people tend to behave (Elsbach \& Kramer, 2003). This social influence process, more than the objective creativity of the idea itself, could help explain why narcissists have been described as "visionaries" by people who have observed them in innovative contexts (Deutschman, 2005: 44). Narcissism and Group Creativity 
We claim that narcissism may not stimulate individual creativity, but what about the link between narcissism and creative performance in groups? Here we extend our analysis to the group level by addressing the following question, "When it comes to creativity, are two (or more) narcissists better than one?" Group creativity depends heavily on the open expression of ideas because people may extend, combine, and improve upon the contributions made by others (Nijstad, Stroebe \& Lodewijkx, 2002). Unfortunately, many good ideas remain unexpressed, leading groups to underperform compared with individuals who work alone (Diehl \& Stroebe, 1987). Competition can serve as an effective stimulant of creative ideas because the need for superiority motivates people to express ideas they might otherwise withhold from the group discussion (Dugosh \& Paulus, 2005; Munkes \& Diehl, 2003).

Consistent with this perspective, research on social motives has shown that groups of people with a pro-self orientation (i.e., the goal is to maximize one's own outcomes relative to others) are more creative than groups of people with a pro-social orientation (i.e., the goal is to cooperate to maximize outcomes for both oneself and others) (Beersma \& De Dreu, 2005). In a similar vein, groups of people primed to be individualistic generated more novel ideas than groups of people primed to be collectivistic (Goncalo \& Staw, 2006). Taken together, these streams of research suggest that the creative potential of groups may be realized when the drive to be superior compels each group member to attempt to propose the most novel ideas (Beersma \& De Dreu, 2005; Dugosh \& Paulus, 2005; Munkes \& Diehl, 2003). Given that narcissists crave attention and recognition for their valued attributes and contributions (e.g., John \& Robbins, 1994), competition between narcissistic group members may lead the group to uncover new sources of information and new perspectives that can then be recombined to generate novel ideas (De Dreu, Nijstad \& van Knippenberg, 2008). 
In particular, narcissists may actually contribute to a more efficient exchange of ideas by reducing production blocking (Diehl \& Stroebe, 1987). Production blocking is caused by group members listening to other group members' ideas and waiting until the other person has finished before expressing his/her idea (Nijstad, et al, 2002). Highly narcissistic individuals may be less patient with such turn-taking (and tend to "break into" the other person's turn), or not listen as attentively to the other person's ideas (and thereby be less likely to forget their own ideas). This self-focus could reduce production blocking and thereby increase the group's creative output. ${ }^{1}$ Indeed, there is recent evidence that people in competitive groups are more likely to interrupt their teammates to express their own ideas and that doing so actually increases the total number of ideas expressed (Goncalo \& Kim, 2010).

Yet, the relationship between narcissism and creativity in groups may be more complex than a direct linear association. As more narcissists join the mix, competition can escalate to the point of obstructing the group's ability to reach closure, synthesize new ideas, and complete tasks on time (Jehn \& Mannix, 2001). Groups with lower levels of competition may be more efficient and more capable of coordinating their efforts, which would be an advantage when the group moves beyond the idea generation stage to actually select an idea and bring it to fruition (Rietzschel, Nijstad \& Stroebe, 2006). Given these tradeoffs, we predict a curvilinear, inverted U-shaped relationship: the more narcissists there are in the group, the more creative the group's performance will be up to an inflection point when additional narcissists begin to have a negative effect on group creativity.

\section{Summary of Predictions and Overview of Studies}

We report the results of three studies in which we investigated the link between narcissism and creativity at the individual, relational, and group levels of analysis. In Study 1, we 
draw on two classic creativity tests to examine our prediction that narcissists are not necessarily more creative than non-narcissists, but they nonetheless judge their own efforts as being more creative. In Study 2, we look at how observers evaluate the creativity of others' ideas. Although narcissists do not necessarily generate more creative ideas, they may be able to convince others that these ideas are more creative because their high levels of confidence, enthusiasm, and charisma correspond to commonly held prototypes of the creative personality (Runco \& Baleda, 1986; Katz \& Giacomelli, 1982). Finally, in Study 3, we turn to the generation of creative ideas in a group context. We expect that groups with more narcissists will be more creative, but as narcissists represent a greater proportion of group membership, their positive influence on group creativity will diminish.

\section{Study 1}

Participants: Participants were 244 undergraduates from a large university on the east coast of the United States who participated in exchange for partial course credit. Men comprised $52 \%$ of the sample. ${ }^{2}$

Narcissism measure: To assess each individual participant's level of narcissism, we used the abridged Narcissistic Personality Inventory (NPI-16) created by Ames, Rose, and Anderson (2006). According to the authors, The NPI-16 is a short measure of subclinical narcissism that has shown meaningful face, internal, discriminant, and predictive validity. Using items that are drawn from the longer narcissistic personality inventory (NPI-40) developed by Raskin and Terry (1988), the NPI-16 instructs respondents to read 16 pairs of statements and choose the one that comes closest to describing their true feelings or beliefs. A sample pair of descriptive statements would read "I really like to be the center of attention" and "It makes me uncomfortable to be the center of attention." Each of the 16 pairs has one statement that is 
consistent with narcissism and one that is not. The scale is scored by counting the number of responses consistent with narcissism $(M=6.74 ; S D=3.11)$. The scale was moderately reliable $(\alpha=.72)$.

Creativity tasks: We measured creativity using two tasks: the Alternate Uses Test (Guilford, 1956) and Ward's (1994) measure of structured imagination. First, the Alternate Uses Test assesses the ability to think divergently, defined as the generation of solutions that move outward from a problem in many different directions (Guilford, 1956). People who think divergently are able to generate a large number of ideas (fluency) that are different from one another (flexibility) (Guilford, 1956). Wallace and Baumeister (2002) employed the Alternate Uses Test to investigate a link between narcissism and task effort, so focused only on the sheer number of ideas generated. We extend this past research by investigating the question of whether narcissists generated alternate uses that were in fact more divergent. Second, Ward's (1994) measure of structured imagination gauges the extent to which people can overcome the constraints of past experience to generate a product that represents a novel departure from existing knowledge. Most people find it difficult to overcome these constraints. For instance, people who are instructed to imagine space creatures that are different "beyond their wildest" imaginations often come up with aliens that have human characteristics such as bilateral symmetry (Ward, 1994).

Two weeks after participants completed the NPI-16, they were given the creativity tasks (we created a delay between these measures to minimize demand effects). On the first task, we asked participants to generate as many alternative uses for a brick as possible in 10 minutes (Guilford, 1956). No further instructions were given. Participants recorded their ideas on a lined sheet. On the second task, we asked participants to "imagine going to another galaxy in the 
universe and visiting a planet very different from Earth" (Ward, 1994). Participants were then given 7 minutes to draw a picture of an animal that is "local to this other planet."

After completing each task, participants were instructed to fill out a brief questionnaire in which they were asked to evaluate the creativity of their own work. They assessed their performance on the Alternate Uses Test by indicating the extent to which they agreed with each of the following four questions: (1) "The alternative uses for a brick I came up with were highly creative," (2) "I probably came up with at least one use for a brick that no one else in this class came up with," (3) "My performance on the uses for a brick test probably shows that I am more creative than most people," (4) "The alternative uses for a brick I came up with are probably very conventional (reverse scored)." Responses to the scale were reliable $(\alpha=.80)$ and so they were averaged together $(M=3.14 ; S D=.89)$. Participants also assessed their performance on the structured imagination task by answering the same set of questions (e.g., "The space creature I drew was highly creative"). Each item was rated on a 7-point scale ranging from 1= "not at all" to $7=$ "completely." Responses to the scale were moderately reliable $(\alpha=.78)$. Therefore, we averaged participants' responses to these questions to create an overall measure of perceived creativity $(M=2.98 ; S D=.92)$.

Creativity coding: The Alternate Uses Test was scored by first counting the sheer number of uses listed (fluency) and then coding the ideas for the extent to which the solutions were qualitatively different from each other (flexibility) (Guilford, 1956). Fluency was assessed by a direct count of the number of alternatives listed. Flexibility was calculated based on the ratings of two coders who were blind to the hypotheses of the study. The coders independently sorted the entire sample of ideas $(n=4,571)$ into categories based on how similar they were to each other; for instance, all the ideas suggesting that the brick be used to build something were 
placed in one category, etc. We then counted the number of categories of ideas generated by each participant. Coders reached significant agreement on the number of categories covered by each individual $(I C C=.86, p<.01)$; therefore their category counts were averaged together $(M=$ 10.71; $S D=4.19$ ). Participants who generated ideas that crossed many categories had higher flexibility than participants whose ideas crossed fewer categories. People who are able to think divergently generate more ideas that cross more categories.

Following directly from previous research (e.g., Ward, 1994), structured imagination was coded from the atypicality of the space creatures' sensory organs. Three trained coders who were blind to the study hypotheses assessed the drawings and accompanying descriptions for evidence of "atypical" sensory organs. Following Ward's original coding scheme, space creatures were considered atypical if they (a) lacked a major sensory organ (i.e., eyes, ears, nose), (b) had atypical numbers of a sensory organ (e.g., three eyes), (c) demonstrated an unusual configuration of the senses (e.g., eyes located below the nose), (d) had an exaggerated or unusual ability (e.g., eyes that had laser beams), or (e) served an atypical function (e.g., ears for protection). The total number of atypical features was tallied for each participant. The ratings of the two coders reached significant agreement $(I C C=.77, p<.01)$ and so their ratings were averaged together to create an overall measure of creative performance $(M=3.10 ; S D=1.58)$.

\section{Results and Discussion}

Narcissism, creative performance, and perceptions of creativity: A bi-variate correlation showed that narcissism was not significantly associated with fluency $(r=.08, n s)$ or flexibility $(r$ $=.06, n s)$. To investigate whether more narcissistic individuals would view their own ideas as more creative, regardless of their objective performance, we conducted linear regressions in which we controlled for fluency and flexibility (these variables were significantly correlated, $r=$ 
$.85, p<.05)$. As predicted, narcissism was positively associated with self-ratings of creativity when controlling for fluency $(\beta=.22, p<.01)$ and flexibility $(\beta=.24 p<.05)$ even though, as one would expect, both fluency $(\beta=.42, p<.01)$ and flexibility $(\beta=.43, p<.01)$ were themselves significantly associated with self-rated creativity.

Despite these results it is possible that narcissists were not necessarily focused on all of their ideas and whether they were different from each other but on whether they generated a few ideas - even one idea they perceived to be extremely original. To address this possibility we conducted an additional analysis in which we counted the number of ideas generated that were so unusual the coders were not able to categorize them. An example of one such idea is, "Use a brick to cast a shadow." The results, however, showed that there was also no significant correlation between narcissism and the number of original ideas generated $(r=-.17, n s)$.

We observed the same pattern of results on the structured imagination task. Narcissism was not significantly associated with the number of atypical features in the space alien drawings $(r=-.05, n s)$. However, as predicted, there was a significant association between narcissism and participants' ratings of the creativity of their own drawings $(r=.27, p<.01)$; even when controlling for the number of atypical features, which was also a significant predictor of selfratings of creativity $(r=.20, p<.01)$.

Together, these results indicate that narcissists (or those who score relatively higher on a standardized measure of subclinical narcissism) saw their own performance as being more creative, unique, and novel, although an assessment made by independent judges revealed no discernible difference on these dimensions.

Study 2 
In Study 2 we investigated whether more narcissistic people are perceived to be more creative than less narcissistic people because their confidence and enthusiasm matches the prototypes people have about highly creative individuals. We predict that highly narcissistic individuals will suggest ideas that are not objectively more creative but are perceived by evaluators as more creative than those suggested by individuals who are less narcissistic. Participants: Participants were 76 students from a large university on the west coast of the United States who completed the study in exchange for course credit. Men comprised $64 \%$ of the sample.

Procedure: Participants were randomly assigned to an experimental session and arrived in pairs. At the beginning of the study, the experimenter randomly selected one person to assume the role of the pitcher and the other to assume the role of the evaluator. Each participant's role was explained directly to him or her after being seated alone in a separate room. The participant who was randomly selected to assume the pitcher role was told, "We are interested in how people behave during pitch meetings when one person tries to sell their ideas to another person. In this study we will focus on new movie ideas and you have been assigned to play the role of the 'pitcher.' This role involves (1) coming up with a new movie idea, (2) developing and rehearsing a pitch that you will use to sell your idea to an evaluator and (3) actually pitching your idea."

Pitchers were also told that the ideas they generated would be scored by their evaluators and that the pitcher who received the highest score (across all the experimental sessions) would receive an additional cash prize of 50 dollars. In fact, at the end of the experimental session, one participant was randomly awarded the 50 dollar prize, although debriefing conversations indicated that all the participants believed the cash prize was real and felt motivated to obtain it. 
After receiving their instructions, pitchers were given 10 minutes to come up with a new movie idea and to rehearse their pitch. Each was provided with 5 sheets of scratch paper and a pen and informed that the actual pitch would last no longer than 10 minutes.

The experimenter then entered the room in which the evaluator was seated and informed him or her that, "We are interested in how people behave during pitch meetings when one person tries to sell their ideas to another person. In this study we will focus on new movie ideas and you have been assigned to play the role of the 'evaluator.' This role involves (1) listening to someone pitch a new movie idea, and (2) deciding whether you, as an evaluator, think the idea is good enough to actually produce." Each participant was then given 10 minutes to think about the criteria they would use to evaluate the new movie idea and to write the criteria on the scratch paper provided.

After 10 minutes elapsed, the pitcher was escorted into the next room and seated across the table from the evaluator. Both were then told, "As you already know, we are interested in how people behave during pitch meetings when one person tries to sell their ideas to another person. In this study we are interested in new movie ideas and one of you has been assigned to play the role of the pitcher and the other the role of evaluator. You will have 10 minutes to make your pitch. Evaluator, please listen to the pitch silently. You will be asked to make your judgment about the idea after the pitch is complete."

The experimenter returned after 10 minutes elapsed and escorted the pitcher back to the rehearsal room. In the meantime, the evaluators were instructed to sit quietly and informed that the experimenter would return with a survey. Once the pitcher had been seated in a separate room, the evaluators were then given 10 minutes to complete a brief questionnaire in which they 
were asked to rate the creativity of the movie idea and their impressions of the individual who pitched it.

Narcissism measure. Once again, we relied on the abridged version of the Narcissistic Personality Inventory (NPI-16) to measure participants' levels of narcissism (Ames et al., 2006). Specifically, we asked the pitchers to complete this measure and scored their responses in the same manner as described in Study $1(M=5.48 ; S D=2.84)$. The reliability of the scale was modest $(\alpha=.65)$ but similar to the scale reliability reported in previous research (Ames et al, 2006).

Creativity ratings. The evaluators were asked to rate the creativity of the movie idea that was pitched to them by responding to the following four items: (1) The movie idea is creative, (2) This movie idea is more creative than the movies that have been at the theaters lately, (3) Other people will think that this movie idea is creative, and (4) It is unlikely that anyone has come up with a movie idea like this before. Each of these four items was rated on a 7-point scale ranging from $1=$ "strongly disagree" to $7=$ "strongly agree." The scale was moderately reliable $(\alpha=.79)$ and so the items were averaged to generate an overall measure of perceived creativity $(M=3.80 ; S D=1.18)$

Creative personality type: The evaluators were also asked to rate their impressions of the pitcher's "energy" by responding to the following four items: (1) The pitcher was charismatic, (2) The pitcher was witty, (3) The pitcher was extreme, and (4) The pitcher was enthusiastic. Each of these four individual traits was rated on a 7-point scale ranging from 1= "strongly disagree" to $7=$ "strongly agree." The scale was moderately reliable $(\alpha=.75)$ and so the items were averaged to create an overall measure of perceived creative personality $(M=3.74 ; S D=$ .96). We chose to focus on these four personal characteristics because they have been shown in 
previous research to correspond to prototypes that people hold about highly creative personalities. In particular, these characteristics have been shown to predict attributions of creativity in the context of Hollywood pitch meetings (see Elsbach \& Kramer, 2003 for a complete description).

Control variables: Despite the results of Study 1, we sought to rule out the possibility that the narcissists in our second study may have been able to generate movie ideas that are objectively more creative. To test this alternative explanation, we evaluated the creativity of the movie ideas based on the pitchers' written descriptions. Following the definition of a creative idea as one that is both novel and feasible (Amabile, 1982), two blind coders independently rated each pitch using two 5-point scales with $1=$ "not at all feasible" and $5=$ "extremely feasible" and $1=$ "not at all novel" and $5=$ "extremely novel." The coders reached significant agreement on both their ratings of novelty $(I C C=.81)$ and feasibility $(I C C=.92)$ so their scores were averaged together. In addition, we also controlled for the sex composition of the dyad to rule out the possibility that evaluations were driven by sex differences (Mannix \& Neale, 2005). In our analysis, mixed sex dyads were coded " 1 " and same sex dyads were coded " $0 . "$

\section{Results}

Perceptions of creativity: Consistent with our prediction, narcissism was significantly correlated with the evaluators' rating of creativity, $(\beta=.30, p<.05)$, controlling for the sex composition of the dyad, $(B=.35, p<.05)$. We also expected that narcissists would be perceived by evaluators as having personal characteristics that match the prototype of a highly creative personality. In line with this prediction, narcissism was significantly correlated with the prototype of a creative personality $(B=.32, p<.05)$, controlling for the sex composition of the dyad, $(ß=.34, p<.05)$. 
To replicate the results of Study 1, we also investigated the possibility that narcissists may have generated more creative ideas. Given that creativity is defined as an idea that is both novel and feasible we averaged the novelty and feasibility ratings to create a composite measure. Again, narcissism was not correlated with the creativity of the ideas pitched $(r=-.00, n s)$. Novelty and feasibility are often negatively correlated (e.g., Rietzschel, Nijstad \& Stroebe, 2010) and the same pattern emerged in our data as well $(r=-.42, n s)$; therefore we also analyzed novelty and feasibility separately. Again, the results showed no correlation between narcissism and the novelty of the ideas pitched $(r=.22, n s)$, nor between narcissism and the feasibility of the ideas pitched $(r=-.24, n s)$. Consistent with the results of Study 1, there was no indication that narcissism contributed to actual creative performance.

Mediation analysis: The results indicate that narcissists pitched ideas that were perceived to be more creative than the ideas pitched by non-narcissists. We wanted to see if this effect was mediated by evaluators' impressions of narcissists' traits. We followed the procedures recommended by Baron and Kenny (1986) to test for mediation. The independent variable was narcissism ( $1=$ high, $0=$ low), the mediator was the evaluator's impression of the pitcher's energy (e.g., charismatic, enthusiastic) and the dependent variable was the evaluator's rating of the creativity of the movie idea.

First, narcissism (IV) was positively related to impressions of the pitcher's energy (mediator), $\beta=.32, p<.05$. Second, narcissism (IV) was positively related to the evaluator's rating of the movie idea's creativity (DV), $B=.30, p<.05$. Third, impressions of the pitcher's energy (mediator) was significantly related to the rated creativity of the movie ideas (DV), $B=$ $.50, p<.01$. Finally, when both narcissism (IV) and impressions of the pitcher's energy (mediator) were entered into the equation simultaneously, narcissism was not significant, $B=.16$, 
$n s$, and impressions of the pitcher's energy remained significant, $\beta=.44, p<.01$. Given the small sample size, standard procedures advocate the use of a bootstrap analysis to calculate bias corrected and accelerated confidence intervals to evaluate mediation effects (Shrout and Bolger, 2002; Preacher and Hayes, 2004). The analysis yielded a confidence interval around the mediation effect that did not include zero, revealing that the mediation effect was significant, $B=$ $-.35, C I 95 \%=(-.13,-.01), 1,000$ bootstrap re-samples. Thus, we can conclude that evaluators' impressions of the pitcher's energy and enthusiasm mediated the effect of narcissism on evaluations of creativity. Figure 1 summarizes the mediation process.

\section{Discussion}

In sum, these findings suggest that narcissists may be effective at convincing others that their ideas are creative, in part because they convey traits that are closely associated with a creative personality prototype. In specific terms, because narcissists come across as more charismatic, enthusiastic, and energetic, they can persuade their audience that the ideas they advocate are more novel than those advocated by non-narcissists who have ideas that are equally creative, but conveyed with less personal force. We also addressed a potential alternative explanation for the findings in Study 1. It is possible that we did not observe performance differences on the creativity tasks because there was no potential evaluation or reward associated with doing well in that study (Wallace \& Baumeister, 2002). However, the results of Study 2 show that narcissism is not associated with creativity, even when the task has an explicit evaluative component built into it. Therefore, we can have greater confidence that narcissists' evaluations of their own creativity are in fact the result of self-enhancement.

Study 3 
In Study 3, we test the intriguing possibility that having more narcissists in a group can help stimulate collaborative creativity, until a point at which it becomes a detriment.

Sample and procedure: 292 undergraduate students from an introductory course in organizational psychology participated in this study in exchange for partial course credit. Men comprised $53 \%$ of the sample. Each person was randomly assigned to groups of four, resulting in a total of 73 teams.

Each team was asked to analyze a real organization making use of the concepts and methods highlighted in the course. Specifically, they were told to "adopt the clinical pose of a management consultant, endeavoring to understand the organization, to identify its strengths and weaknesses and ultimately to propose actions that solve problems and improve performance." The portion of the paper that is most relevant to this study is the section in which they proposed a solution to the problem they identified. In this section, groups were instructed to generate novel plans that the organization could implement to improve their problems and build on their strengths. The solutions were not intended to be wild or unrealistic. In fact, they were explicitly instructed to come up with feasible action items - things the organization could do given its constraints. Students took these projects seriously because they accounted for $40 \%$ of their overall course grade.

At the beginning of the semester, students were told that their research participation was voluntary, anonymous, and that the information they provided would not be made available to their instructor. Surveys designed to assess the creative process were handed out at the mid-point of the group project, halfway between the assignment to groups, and the final deadline. We chose the mid-point because previous research has shown that the mid-point is when high performing groups experience a concentrated burst of activity at which time they debate competing task- 
related perspectives (Gersick, 1988). Therefore, it is at this particular stage of a group's development when the creative process might be most relevant.

Independent variable: Our primary independent variable was the average narcissism score of each group. At the beginning of the semester, participants completed the abridged Narcissistic Personality Inventory (NPI-16) prior to being assigned to a group project team $(M=$ $6.79 ; S D=1.67)$. The reliability of the scale was $\alpha=.72$.

Dependent variable: Assessments of individual creativity typically focus either on the process of being creative or on an objective product that can be rated by outside observers (Amabile, 1982). Scholars who focus on the former typically assess cognitive processes that are believed to be associated with creative problem solving (Simonton, 2003). For instance, the creative process at the individual level requires some capacity to generate novel alternatives or remote associations and these abilities are assessed using creativity tests (Guilford, 1967; Mednick, 1962). Scholars who take the latter approach typically use outside raters to judge the creativity of products (e.g., MacKinnon, 1962; Amabile, 1982).

This distinction between process and product is relevant to group creativity as well. A creative group process requires systematic information processing whereby a wide range of ideas are both expressed and thoughtfully deliberated (De Dreu et al., 2008), while a creative group product is one that can be rated by outside observers on the extent to which it represents a novel and appropriate solution (Amabile, 1982). With this distinction in mind, we decided to measure group creativity on both dimensions following from our prediction that the presence of narcissists should motivate the group to consider more task-related alternatives (systematic thinking) and deliver a solution that is a departure from the status quo (creative product). These measures are described in detail below. 
Systematic thinking. Each group member responded to four survey questions: (1) "My group tries to consider all possible alternatives before making decisions," (2) "My group is extremely thorough when making decisions," (3) "My group debates many ideas before making decisions," (4) "My group thinks deeply before making decisions" drawn from previous research (see De Dreu et al, 2008 for a review). They responded on a 5-point scale where $1=$ "strongly disagree" and 5 = "strongly agree." This measure was computed by aggregating data gathered at the individual level (Kozlowski \& Klein, 2000). Therefore, we calculated two indicators of within-group agreement to justify aggregation: The $r_{W G}$ within group agreement measure (James, Demaree \& Wolf, 1984) and the intra-class correlation coefficient, ICC(1) (James, 1982). Following previous research (Kozlowski \& Klein, 2000), we adopted a cutoff of .70 or higher for the $r_{\mathrm{WG}}$ and a cutoff of .20 for the $I C C$ (1) scores. The $r_{\mathrm{WG}}$ was .85 and $I C C(1)$ was $.77(F=$ $9.97, p<.01)$ indicating significant within-group agreement on the group's creative process, thus justifying the aggregation of individual scores to the group level $(\underline{M}=4.28 ; S D=.62)$.

Group product: The creativity of each group's project was rated by two independent coders who were blind to our hypotheses. Specifically, the coders rated the extent to which each solution was either radical or incremental because, assuming the solutions are practical, creative solutions are characteristically novel in the sense that they depart from existing approaches (Simonton, 2003). Therefore, each team's term paper was coded on the following 5-point scale: $1=$ "extremely incremental (no change or almost no change recommended," 2 = "incremental (something that can already be done within the current system)," $3=$ "neither radical nor incremental," 4 = "radical (a proposal that required a major change)," and 5 = "extremely radical (a change that would completely overhaul the organization's current approach)." The coders 
reached significant agreement $(I C C=.75, p<.01)$ and so their scores were averaged to create a single measure of group creativity $(\underline{M}=3.02 ; S D=1.00)$.

Control variable: It is possible that groups with more narcissistic members were less cooperative. As a consequence, these teams may have chosen to meet less frequently to discuss the project during the course of the semester and adopted a more independent work style that influenced group creativity in a positive way (Nemeth \& Goncalo, 2005). To rule out these effects, we asked each group member to estimate the total number of times they met to discuss the project, averaged their estimates $(\underline{M}=4.60, S D=1.41)$ and controlled for it in our analyses.

\section{Results and Discussion}

We analyzed the data using two hierarchical linear regressions in which the control variable was entered on the first step and the independent variables were entered on the second step. Because we predicted a curvilinear effect of narcissism on group creativity, we created a quadratic term by squaring the number of narcissists in each group and included this quadratic term in each regression analysis. Finally, we also controlled for the standard deviation of narcissism in each group in addition to the mean to control for within group variation. This approach follows that used in several previous research studies (e.g. Barrick, Stewart, Neubert, \& Mount, 1998).

In Model 1, the dependent variable is the group's creative process. The meeting frequency variable was not significant $(\beta=.02, n s)$, neither was the standard deviation of narcissism within each group $(\beta=-.22, n s)$. The results showed a positive but only marginally significant linear effect of narcissism on group creativity $(\beta=2.04, p<.01)$ and a significant curvilinear effect of narcissism on group creativity $(\beta=-2.27, p<.01)$. The coefficient of the quadratic term was negative indicating that the relationship between narcissism and creativity 
had an inverted U-shape. The inflection point was calculated by taking the partial derivative as recommended by Aiken and West (1991). The inflection point equaled 6.48. In other words, group creativity increased as the mean level of narcissism in the group increased up to a point approaching a narcissism score of 7 , at which point group creativity began to diminish (See Figure 2).

In Model 2, the dependent variable is the groups' creative product. The meeting frequency variable was not significant $(\beta=.09, n s)$, and neither was the standard deviation of narcissism in each group $(\beta=-.07, n s)$. The linear effect of the narcissism measure on group product creativity was positive and significant $(\beta=1.63, p=.01)$ and the curvilinear effect of narcissism on group product creativity was negative and significant $(\beta=-1.92, p<.01)$. The coefficient of the quadratic term indicates that the relationship between narcissism and creativity had an inverted U-shape. Again, we calculated the inflection point, which equaled 6.13. That is, the creativity of the group product increased as the mean level of narcissism in each group increased up to a narcissism score of approximately 6 , at which point group creativity began to diminish (See Figure 3). Taken together, these results suggest that the creativity of both the group process and product were facilitated by the presence of more narcissistic individuals up to a point at which increasing narcissism became detrimental.

\section{General Discussion}

We argued that narcissists are not necessarily more creative than other people but simply think they are. Nevertheless, the enthusiasm with which they "sell" their ideas may elicit more favorable evaluations of creativity relative to their less narcissistic peers (Kasof, 1995). Consistent with this prediction, we found in Study 1 that narcissists evaluated their own creative talents more positively than did non-narcissists, but their alleged creativity was not supported by 
objective measures of their performance. The results of Study 2, however, demonstrated that evaluators believed the ideas pitched by narcissists were more creative and these perceptions were fully mediated by their impressions of narcissists as enthusiastic and charismatic. Therefore, in contexts where there are no objective standards for judging creativity, narcissists may be adept at getting people to share their inflated self-views.

In Study 3 we extended our investigation to the group level of analysis where the creative process becomes interactive and requires the motivation to fully explore and consider alternative points of view (De Dreu et al, 2008). On two measures of group creativity, one that focused on systematic thinking and the other on the product itself, groups with approximately two narcissistic members (out of four) outperformed groups with too many or too few. In short, narcissists can contribute to creativity in groups even if they may not perform creatively while working alone. The notion that more narcissists are better for group creativity is counterintuitive, certainly more counterintuitive than the notion that groups with a higher percentage of members who are open to new experience and tolerant of ambiguity tend to be more creative (Baer, Oldham, Jacobsohn, \& Hollingshead, 2008). But, the same needs for recognition and power that cast a dark shadow on narcissists may position them as catalysts for creative colloquy.

\section{Theoretical contributions and future directions}

Our results build upon existing research in several important ways. First, we draw attention to the link between narcissism and attributions of creativity (Kasof, 1995). Garnering recognition for one's creative achievements requires some skill in the art of persuasion, particularly in less paradigmatic fields in which there are fewer objective standards to determine whether one idea is more creative than another (Kuhn, 1962). Future research might investigate 
other traits that make some people especially skilled at this endeavor. For instance, high selfmonitors may be able to convince people their ideas are creative because they are able to detect subtle cues about how creativity is evaluated in different contexts (Snyder, 1974).

Our findings that narcissists are viewed as more creative than an objective evaluation of their work would warrant may have potentially disturbing implications for the way the process of evaluating ideas plays out over time. In most fields there is a selection process whereby some ideas are determined to be highly creative and therefore worthy of being disseminated and adopted while others ideas are deemed not worthy of such attention (Csikszentmihalyi, 1988). Ideally, this process would be relatively objective and higher quality ideas should have a higher probability of selection than others (Simonton, 2003). Our results, however, suggest that this process can be contaminated when evaluations of creativity are overly influenced by the behavioral style with which they are communicated, particularly in fields that lack objective performance criteria (Barron, 1965). In such fields, creative output may gradually decline as true creative talent is continuously traded for charisma and enthusiasm.

Creativity is a complex and multi-faceted construct, and there are many ways to measure it; therefore it would be unrealistic to claim that our conclusions regarding the link between narcissism and creativity are definitive. For instance, Raskin (1980) reported a small but significant correlation between narcissism and the Barron Symbolic Equivalence Test (1967), though it should be noted that this relationship did not remain significant when controlling for self-reported creativity. Nevertheless, future research might examine the link between narcissism and creative performance using other tasks and perhaps longitudinal methods in which narcissism is linked to creative achievement over time (e.g., Helson, Roberts, \& Agronick, 1995). 
Future research might also differentiate between the influence of narcissism on creativity and the influence of other forms of positive self-evaluation such as self-esteem, self-acceptance, confidence or self-efficacy (Tierney \& Farmer, 2002). Such traits might be mistaken for narcissism in social interactions, but whereas these other traits have established links to individual creativity, narcissism does not. This may be why the stereotype of highly creative people as narcissistic is so enduring: legitimately creative people may often be viewed as narcissistic when this is not the case while narcissists often pass as highly creative when they may in fact lack creative talent.

Finally, the results of Study 3 demonstrated a curvilinear effect of narcissistic group composition with an inflection point at 2 narcissistic group members. Future research might investigate groups of varying size to determine whether having two narcissists in a group of any size is sufficient to produce these benefits or whether it is critical that narcissists not comprise the majority of the group.

\section{Conclusion}

The results of three studies suggest that whether narcissism actually contributes to creative performance or whether the presence of that trait simply creates an unfounded impression of creative talent may depend on the unit of analysis. Therefore, an important strength of this research is that we examined creativity at multiple levels to derive a more complete picture of how narcissism might contribute to (or mislead) creative problem solving efforts. The results suggest that to capitalize on the narcissists in our midst, we should collaborate with them and encourage them to collaborate with each other. In so doing, groups could turn what is often considered a decidedly negative trait into a valuable source of creative tension. 


\section{References}

Aiken, L. S., \& West, S. G. (1991). Multiple regression: Testing and interpreting interactions. Thousand Oaks, CA: Sage.

Amabile, T.M. (1982). Social psychology of creativity: A consensual assessment technique. Journal of Personality and Social Psychology, 43, 997-1013.

Ames, D.R., Rose, P., \& Anderson, C.P. (2006). The NPI-16 as a short measure of narcissism. Journal of Research in Personality, 40, 440-450.

Baer, M., Oldham, G.A., Jacobsohn, G.C. \& Hollingshead, A.B. (2008). The personality composition of teams and creativity: The moderating role of team creative confidence. Journal of Creative Behavior, 42, 255-282.

Barron, F. (1965). The psychology of creativity. In New Directions in Psychology (vol. 2, 1134). New York: Holt, Rinehart \& Winston.

Barron, F. (1967). Symbolic Equivalence Test, unpublished test.

Barron F. \& Harrington, D. (1981). Creativity, intelligence, and personality. In M. Rosenzweig \& L. Porter (Eds.), Annual review of psychology (Vol.32, pp.439-476). Palo Alto, CA: Annual Reviews.

Baron, R.M. \& Kenny, D.A. (1986). The moderator-mediator variable distinction in social psychological research: Conceptual, strategic and statistical considerations. Journal of Personality and Social Psychology, 51, 1173-1182.

Beersma, B. \& De Dreu, C.K.W. (2005). Conflict's consequences: The effects of social motives on post-negotiation creative and convergent group functioning and performance. Journal of Personality and Social Psychology, 89, 3, 345-357. 
Bogart, L.M., Benotsch, B.G. \& Pavlovic, J.L. (2004). Feeling superior but threatened: The relation of narcissism to social comparison. Basic and Applied Social Psychology, 26, $35-44$.

Brunell, A.B., Gentry, W.A., Campbell, W.K., Hoffman, B.J., Kuhnert, K.W., \& DeMarree, K.G. (2008). Leader emergence: The case of the narcissistic leader. Personality and Social Psychology Bulletin, 34, 1663-1676.

Carroll, L. (1987). A study of narcissism, affiliation and power motives among students in business administration. Psychological Reports, 61, 355-358.

Chatterjee, A., \& Hambrick, D.C. (2007). It's all about me: Narcissistic chief executive officers and their effects on company strategy and performance. Administrative Science Quarterly, 52, 351-386.

Csikszentmihalyi, M. (1988). Society, culture and person: A systems view of creativity. In R.J. Sternberg (Ed.) The Nature of Creativity: Contemporary Psychological Perspectives. Cambridge University Press.

De Dreu, C. K. W., Nijstad, B. A., \& van Knippenberg, D. (2008). Motivated information processing in group judgment and decision making. Personality and Social Psychology Review, 12, 22-49.

Diehl, M., \& Stroebe, W. (1987). Productivity loss in brainstorming groups: Toward the solution of a riddle. Journal of Personality and Social Psychology, 53, 497-509.

Deutschman, A. (2005). Is your boss a psychopath? Fast Company, 96, 44-52.

Dugosh, K.L. and Paulus, P.B., (2005). Cognitive and social comparison processes in brainstorming. Journal of Experimental Social Psychology, 41, 313-320.

Duncker, K. (1945). On problem solving. Psychological Monographs, 58, (Whole No. 270). 
Elsbach, K.D. \& Kramer, R.M. (2003). Assessing creativity in Hollywood pitch meetings:

Evidence for a dual process model of creativity. Academy of Management Journal, 46, 283-301.

Farwell, L. \& Wohlwend-Lloyd, R. (2008). Narcissistic processes: Optimistic expectations, favorable self evaluations, and self-enhancing attributions. Journal of Personality, 66, $65-83$

Gersick, C. (1988). Time and transition in work teams: Toward a new model of group development. Academy of Management Journal, 32, 274-309.

Goncalo, J.A. \& Staw, B.M. (2006). Individualism-collectivism and group creativity. Organizational Behavior and Human Decision Processes, 100, 96-109.

Goncalo, J.A. \& Kim, S.H. (2010). Distributive justice beliefs and group idea generation: Does a belief in equity facilitate productivity?" In press at Journal of Experimental Social Psychology.

Guilford, J.P. (1956). The structure of intellect. Psychological Bulletin, 33, 267-293.

Guilford, J. P. (1967). The Nuture of Human Intelligence. New York: McGraw-Hill.

Helson, R., Roberts, B. \& Agronick, G. (1995). Enduringness and change in creative personality and the prediction of occupational creativity. Journal of Personality and Social Psychology, 69, 1173-1183.

James, L. R. (1982). Aggregation bias in estimates of perceptual agreement. Journal of Applied Psychology, 67, 219-229.

James, L. R., Demaree, R. G., \&Wolf, G. (1984). Estimating within group inter-rater reliability with and without response bias. Journal of Applied Psychology, 69, 85-98. 
Jehn, K.A. \& Mannix, E.A. (2001). The dynamic nature of conflict: A longitudinal study of intra-group conflict and group performance. Academy of Management Journal, 44, 238251.

John, O.P. \& Robbins, R.W. (1994). Accuracy and bias in self perception: Individual differences in self enhancement and the role of narcissism. Journal of Personality and Social Psychology, 66, 206-219.

Kasof, J. (1995). Explaining creativity: The attributional perspective. Creativity Research Journal, 8, 311-56.

Katz, A. \& Giacommelli, L. (1982). The subjective nature of creativity judgments. Bulletin of the Psychonomic Society, 20, 17-20.

Kernis, M.H. \& Sun, C.R. (1994). Narcissism and reactions to inter-personal feedback. Journal of Research in Personality, 28, 4-13.

Kozlowski, S.W.J. \& Klein, K.J. (2000). A multi-level approach to theory and research in organizations: Contextual, temporal and emergent processes. In K.J. Klein \& S.W.J. Kozlowski (Eds.) Multi-level theory, research and methods in organizations:

Foundations, extensions and new directions, 3-90. San Francisco, CA: Jossey-Bass.

Kuhn, T.S. (1962). The Structure of Scientific Revolutions. Chicago: University of Chicago Press.

Mannix, E. and Neale, M. (2005), What differences make a difference? Psychological Science in the Public Interest, 6, 31-55.

MacDonald, R. \& Wilson, G. (2005). Musical identities of professional jazz musicians: A focus group investigation. Psychology of Music, 33, 395-417. 
MacKinnon, D.W. (1962). The nature and nurture of creative talent. American Psychologist, 17, 485-495.

McCrae, R.R. (1987). Creativity, divergent thinking and openness to experience. Journal of Personality and Social Psychology, 52, 1258-1265.

Mednick, S.A. (1962). The associative basis of the creative process. Psychological Review, 26, $220-232$.

Munkes, J., \& Diehl, M. (2003). Matching or competition? Performance comparison processes in an idea generation task. Group Processes and Intergroup Relations, 6, 305 - 320.

Nemeth, C.J. \& Goncalo, J.A. (2005). Creative collaborations from afar: The benefits of independent authors. Creativity Research Journal, 17, 1-8.

Nemeth, C. \& Wachtler, J. (1974). Creating the perceptions of consistency and confidence: A necessary condition for minority influence. Sociometry, 37, 529-540.

Nijstad, B. A., Stroebe, W., \& Lodewijkx, H. F. M. (2002). Cognitive stimulation and interference in groups: Exposure effects in an idea generation task. Journal of Experimental Social Psychology, 38, 535-544.

Preacher, K. J., \& Hayes, A. F. (2004). SPSS and SAS procedures for estimating indirect effects in simple mediation models. Behavior Research Methods, Instruments, \& Computers, 36, $717-731$

Raskin, R. (1980). Narcissism and creativity: Are they related? Psychological Reports, 46, 5560.

Raskin, R. N., \& Shaw, R. (1988). Narcissism and the use of personal pronouns. Journal of Personality, 56, 393-404. 
Raskin, R. \& Terry, H. (1988). A principal components analysis of the narcissistic personality inventory and further evidence of its construct validity. Journal of Personality and Social Psychology, 54, 890-902.

Rietzschel E, Nijstad B, Stroebe W. (2006). Productivity is not enough: a comparison of interactive and nominal brain-storming groups on idea generation and selection. Journal of Experimental Social Psychology, 42, 244-251.

Rietzschel E, Nijstad B, Stroebe W. (2010). The selection of creative ideas after individual idea generation: Choosing between creativity and impact. In press at British Journal of Psychology.

Runco, M.A. \& Bahleda, M.D. (1986). Implicit theories of artistic, scientific and everyday creativity. Journal of Creative Behavior, 20, 93-98.

Sedikides, C., Rudich, E.A., Gregg, A.P., Kumashiro, M. \& Rusbult, C. (2004). Are normal narcissists psychologically healthy?: Self esteem matters. Journal of Personality and Social Psychology, 87, 400-416.

Shrout, P.E., and N. Bolger. (2002). Mediation in experimental and non-experimental studies: New procedures and recommendations. Psychological Methods, 7, 422-445.

Simonton, D.K. (2003). Scientific creativity as constrained stochastic behavior: The integration of product, person and process perspectives. Psychological Bulletin, 129, 475-494.

Snyder, M. (1974). The self monitoring of expressive behavior. Journal of Personality and Social Psychology, 30, 526-537.

Sutton, R.I. \& Hargadon, A. (1996). Brainstorming groups in context: Effectiveness in a product design firm. Administrative Science Quarterly, 41, 685-718.

Taylor, C.W. \& Barron, F. (1963). Scientific creativity. New York: Wiley. 
Tierney, P. \& Farmer, S.M. (2002). Creative self efficacy: Its potential antecedents to creative performance. Academy of Management Journal, 45, 1137-1146.

Wallace, H. M., \& Baumeister, R. F. (2002). The performance of narcissists rises and falls with perceived opportunity for glory. Journal of Personality and Social Psychology, 82, 819834.

Ward, T.B. (1994). Structured imagination: The role of category structure in exemplar generation. Cognitive Psychology, 27, 1-40.

Watson, P.J., Grisham, S.O., Trotter, M.V., Biderman, M.D. (1984). Narcissism and empathy: Validity evidence for the narcissistic personality inventory. Journal of Personality Assessment, 48, 301-306.

Wiekens, C.J. \& Stapel, D.A. (2008). I versus We: The effects of self-construal level on diversity. Social Cognition, 26, 368-377. 


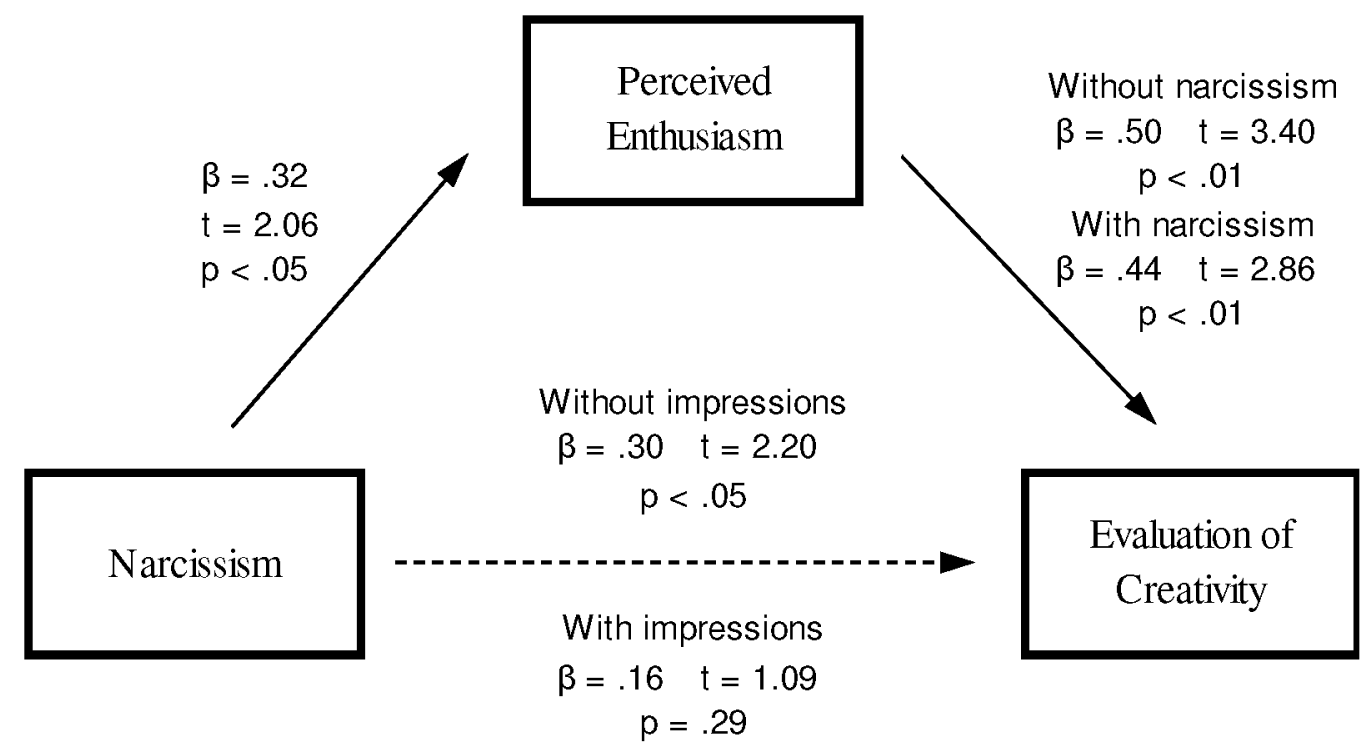

Figure 1. Main and mediating effects of narcissism, impressions of the pitcher and evaluations of creativity. Dotted arrow indicates that a relationship fell below significance in the full model (e.g. that there is full mediation). 


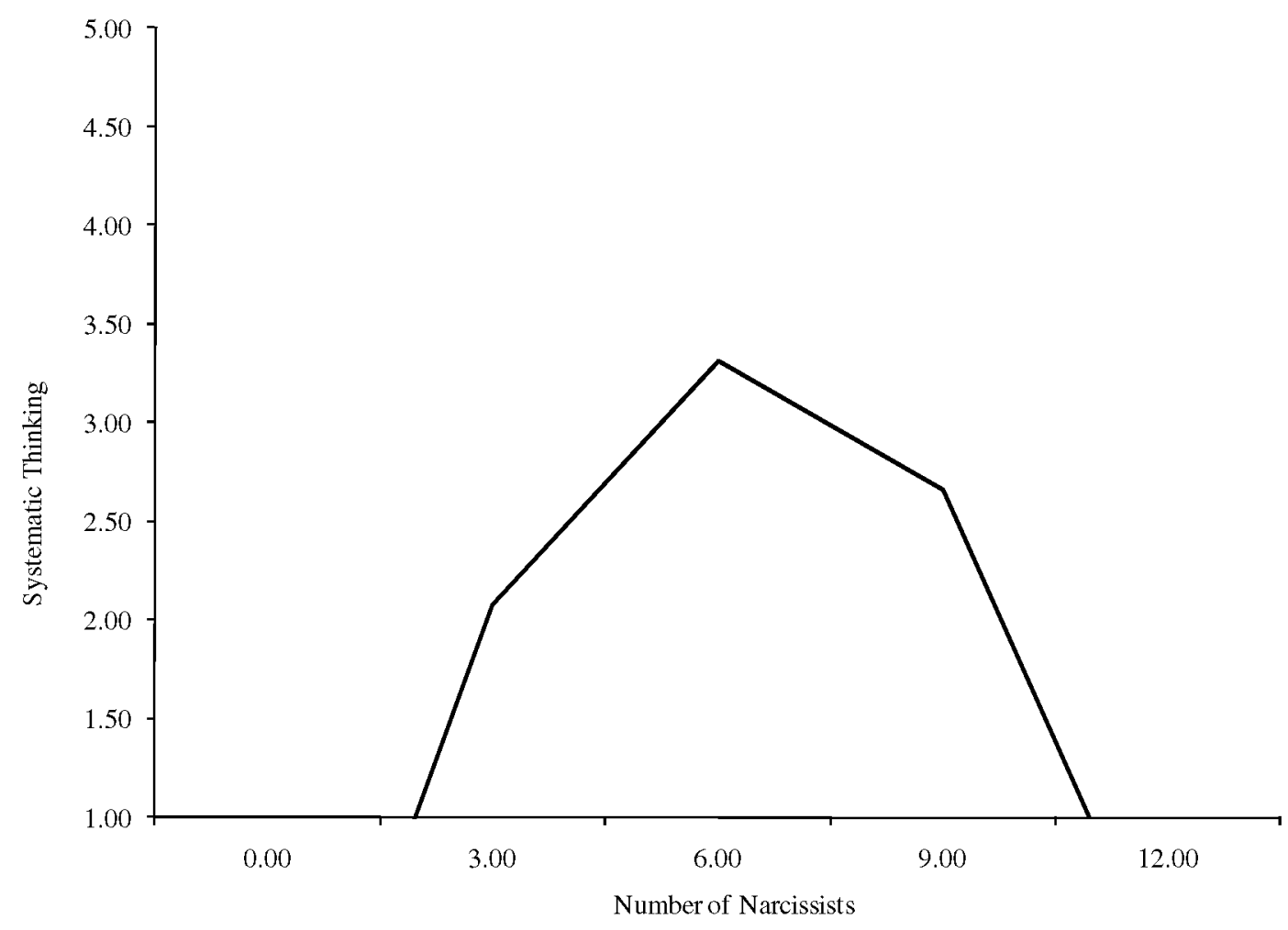

Figure 2. The curvilinear effects of narcissistic group composition on systematic thinking in groups. Systematic thinking increases as the number of narcissists increase to an inflection point of 6.48 . 


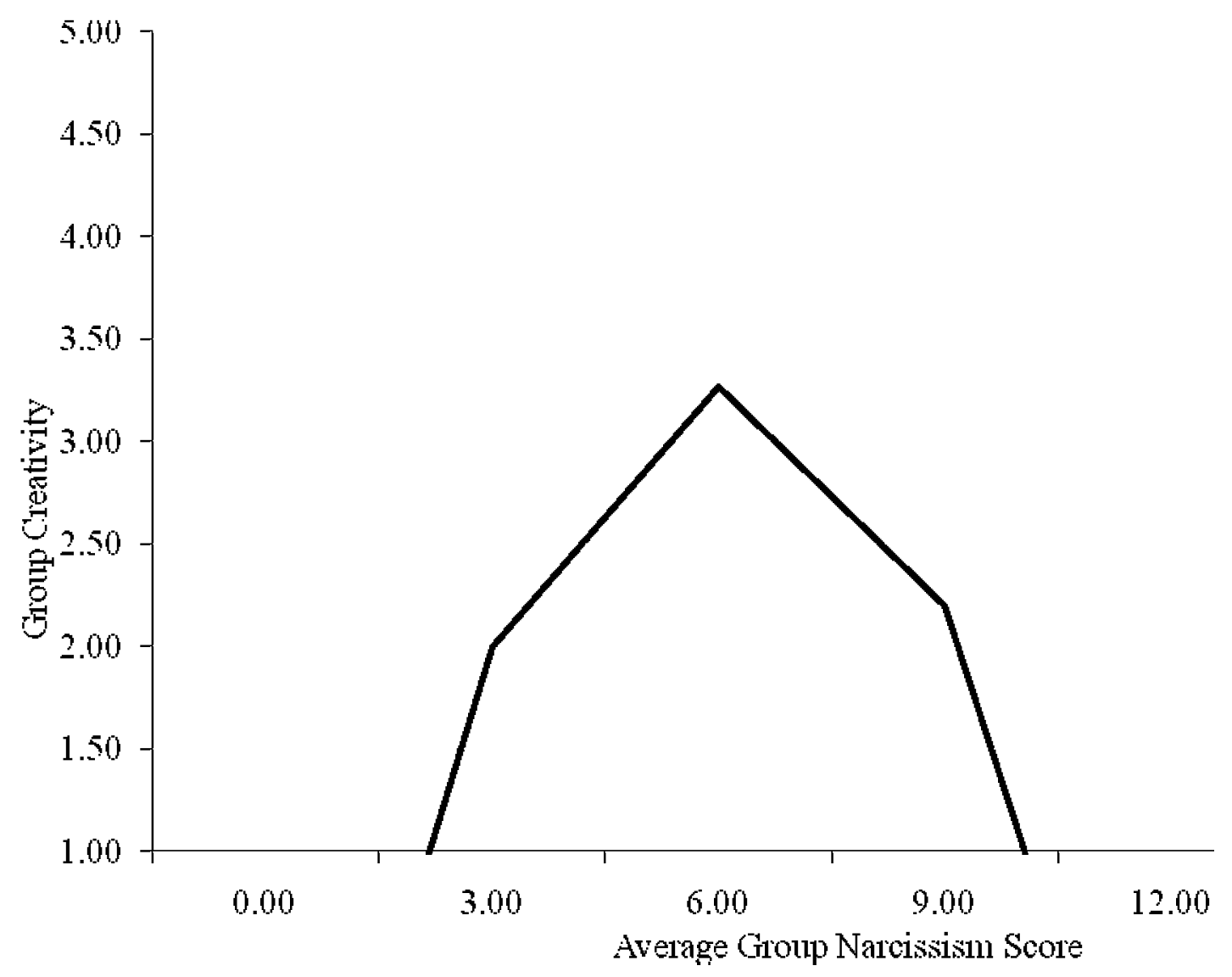

Figure 3. The curvilinear effects of narcissistic group composition on group creativity. Group creativity increases as the average group narcissism score increase to an inflection point of 6.13. 


\section{Endnotes}

\footnotetext{
${ }^{1}$ We thank an anonymous reviewer for suggesting this idea.

${ }^{2}$ We included a control for sex in all of our analyses in study 1 and for the sex composition of each group in Study 3. The control for sex was non-significant in any of the analyses and all of our results held when the controls for sex were included. Therefore, we dropped that variable from our analyses in studies $1 \& 3$.
} 